Научная статья

УДК 339.97(510+7:5-191.2)

https://doi.org/10.24866/1813-3274/2021-3/80-96

\title{
ИНИЦИАТИВА «ПОЯС И ПУТЬ» \\ В КОНТЕКСТЕ АМЕРИКАНО-КИТАЙСКОГО ВЛИЯНИЯ НА ЧЕЛОВЕЧЕСКИЙ КАПИТАЛ ЦЕНТРАЛЬНОЙ АЗИИ
}
В. А. Цибиков ${ }^{1}$, Уральский государственный экономический университет,
г. Екатеринбург, Россия
E-mail: rleah@yandex.ru

Аннотаџия. Глобальная инициатива КНР «Один пояс и один путь», далее - «Пояс и путь» рассматривается не только как совокупность инфраструктурных проектов в сферах социально-экономического развития и безопасности, но и как концепция, фактически обновившая содержание государственной идеологии. Она дополняет национальную доктрину социализма и активно используется для оказания влияния на состояние человеческого капитала стран-участниц. Этому способствуют китайские образовательные и культурные проекты, цифровизация «Пояса и пути», информирование мировой общественности о достигнутых результатах и международная издательская деятельность. Согласно мнению политического руководства США, китайская инициатива реализуется с использованием недобросовестных методов, что, в ряде случаев, сопровождается деятельностью, нарушающей нормы международного права и национальное законодательство стран. Это выражается в условиях труда работников, задействованных в проектах, дезинформации общественности, склонении национальных властей стран-участниц к коррупционным проявлениям и к заключению с китайскими партнёрами «хищнических» (обусловленных) контрактов. В контексте противодействия инициативе «Пояс и путь» осуществляемая Соединёнными Штатами деятельность носит декларативный и, отчасти, запоздалый характер, на сегодняшний момент практически не подкрепляется конкретными действиями и сводится к дискредитации китайских проектов. Реализация же инициативы «Пояс и путь», предложенной Китаем в 2013 г., основана на системе межгосударственного стратегического планирования, осуществляемого через сопряжение национальных стратегий развития и государственных программ.

\footnotetext{
${ }^{1}$ Виктор Александрович Цибиков, кандидат педагогических наук, старший преподаватель кафедры государственного и муниципального управления, Уральский государственный экономический университет, г. Екатеринбург, Россия.
}

(C) Цибиков В. А., 2021 
Ключевые слова: идеология Китая, доктрина социализма, человеческий капитал, человеческий потенциал, Центральная Азия, инициатива КНР «Один пояс - один путь», «Пояс и путь», образовательный проект, культурный проект, экономическая безопасность, средства массовой информации, стратегическое планирование, государственная программа, внешняя политика, внутренняя политика, экономика, стратегия, Китай, США, Казахстан, Туркменистан, Киргизия, Узбекистан, Таджикистан.

Для цитирования: Цибиков В. А. Инициатива «Пояс и путь» в контексте американо-китайского влияния на человеческий капитал Центральной Азии // Азиатско-Тихоокеанский регион: экономика, политика, право. 2021. № 3. С. 80-96. https://doi.org/10.24866/1813-3274/2021-3/80-96.

Original article

\section{THE BELT AND ROAD INITIATIVE IN THE CONTEXT OF THE AMERICAN-CHINESE INFLUENCE ON THE HUMAN CAPITAL OF CENTRAL ASIA}

Viktor A. Tsibikov ${ }^{1}$, Urals State University of Economics, Yekaterinburg, Russia E-mail: rleah@yandex.ru

Abstract. China's global "One Belt and One Road" Initiative, hereinafter - "Belt and Road" is seen not only as a set of infrastructure projects in the areas of socio-economic development and security, but also as a concept that has actually updated the content of the state ideology. It complements the national doctrine of socialism and is actively used to influence the human capital of participating countries. Chinese educational and cultural projects, the digitalisation of the Belt and Road, global awareness of the results achieved and international publishing contribute to this. According to the US political leadership, the Chinese initiative is being implemented using unfair methods, which, in some cases, are accompanied by activities that violate international law and the countries' national legislation. This is manifested in the labour conditions of workers involved in the projects, misinformation of the public, inducing national authorities of the participating countries to engage in corrupt practices and entering into 'predatory' (conditional) contracts with Chinese partners. In the context of countering the Belt and Road, the US' activities are declarative and partly belated, unsupported by concrete actions at the moment and are reduced to discrediting Chinese projects. The implementation of the Belt and Road Initiative by China is based on the system of interstate strategic planning implemented through the conjunction of national development strategies and state programs.

\footnotetext{
${ }^{1}$ Victor A. Tsibikov, Candidate of Pedagogical Sciences, Senior Lecturer of the Department of State and Municipal Governance, Urals State University of Economics, Yekaterinburg, Russia.
} 
Keywords: Chinese ideology, socialist doctrine, human capital, human potential, Central Asia, Chinese initiative, One Belt - One Road, Belt and Road, educational project, cultural project, economic security, mass media, strategic planning, state program, foreign policy, domestic policy, economy, strategy, China, USA, Kazakhstan, Turkmenistan, Kyrgyzstan, Uzbekistan, Tajikistan.

For citing: Tsibikov V. A. The Belt and Road Initiative in the context of the American-Chinese influence on the human capital of Central Asia // PACIFIC RIM: Economics, Politics, Law. 2021. No. 3. P. 80-96. DOI https://doi.org/10.24866/1813-3274/20213/80-96.

По взглядам политического руководства США, изложенным в документе «Новая стратегия США для Индо-Тихоокеанского региона» (официально опубликована в июне 2020 г.), Китай останется доминирующей экономикой региона [22]. Хотя темпы роста Китая замедляются, к 2030 г. прогнозируется увеличение значений показателей его экономического роста более чем на 50\%. Для сохранения стабильности и наращивания потенциала в социально-экономической и иных сферах, усиления позиций в мире Китаем реализуется инициатива «Пояс и путь» (Belt and Road Initiative - BRI). По данным из иных источников, только в 2020 г. китайские компании вложили 110,68 млрд юаней (\$15,96 млрд) в виде нефинансовых прямых инвестиций в 57 стран вдоль «Пояса и пути», что на 25,7\% больше, чем в 2019 г. За тот же период товарооборот Китая со странами вдоль Шёлкового пути составил 6,75 трлн юаней, увеличившись на 1,5\% в сравнении с аналогичным периодом прошлого года [14].

Согласно данным, размещённым на официальном сайте «Belt and Road Initiative» [25], в составе инициативы проекты в сфере транспорта, энергетики, информационно-коммуникационных технологий, градостроения, космической деятельности, туризма, образования и создания специальных экономических зон. Всего 118 наименований. В части, касающейся стран Центральной Азии, проекты отражены в табл. 1.

Для успешной реализации предусмотренных BRI проектов происходит её сопряжение с программами развития и сотрудничества ООН, АCEAH, AC, EC, ЕАЭС и других международных и региональных организаций, а также с национальными стратегиями развития стран, в частности, центральноазиатских государств [4]. В этих целях вносятся целевые мероприятия в документы стратегического планирования и принимаются совместные декларации о намерениях. В частности, в Казахстане [10] в рамках реализации государственной программы инфраструктурного развития «Нұрлы жол» (Светлый путь) на 2015-2019 гг. сформирована оптимальная логистическая цепь от Восточного побережья Китая (порт Ляньюньган), современного мультимодального хаба «Сухой порт» на границе Казахстана и Китая и далее по системе 
железнодорожных и автомобильных магистралей через Каспий в Турцию и Европу. На границе с Китаем сформирован транспортно-логистический и торговый хаб специальная экономическая зона «Хоргос - Восточные ворота». В Киргизии учитывается соседство страны с Китаем, и глобальная инициатива «Пояс и путь» рассматривается как перспектива [12]. При этом руководство Кыргызстана стремится соединить в проводимой политике две глобальные инициативы - ЕАЭС и «Пояс и путь» через продвижение инициативы «Кыргызстан как ворота интеграции ЕАЭС» и проекта «Пояс и путь». Согласно национальной стратегии развития страны планируется в ближайшие пять лет приступить к строительству железной дороги Китай Кыргызстан - Узбекистан и торгово-логистического центра в с. Барпы Сузакского района Джалал-Абадской области Кыргызстана за счёт инвестиций КНР [8]. Стратегией развития Таджикистана до 2030 г. предусматривается развитие потенциала экономических коридоров, соединяющих регионы страны со странами Центральной Азии, Китаем, Афганистаном, Пакистаном, Индией, Юго-Восточной Азией, Россией, Ближним Востоком и другими регионами. В Узбекистане находится в стадии проработки проект по строительству железной дороги Китай - Кыргызстан Узбекистан [7]. Президент Узбекистана Ш. Мирзиёев акцентировал внимание на необходимости наполнения концепции «Пояс и путь» конкретными программами и проектами регионального развития, а также на разработке комплексной программы действий по сотрудничеству в создании транспортно-логистических маршрутов, связывающих Центральную Азию через Китай и Россию с рынками Южной, ЮгоВосточной Азии и европейских стран [17]. В телефонном разговоре с лидером КНР от 29 апреля 2021 г. он подтвердил государственный курс на укрепление взаимосвязанности Центральной и Южной Азии [5], что соответствует стратегии развития страны. При этом в государственные программы Узбекистана мероприятия, позволяющие приступить к реализации проектов «Пояса и Пути», до настоящего момента не включались [11]. Туркменистан является ключевым экономическим партнёром Пекина в Каспийском регионе. Приоритетной сферой сотрудничества сторон является нефтегазовая. Китай является главным покупателем туркменского газа, а также участвует в разработке ряда крупных месторождений природного газа на территории прикаспийской республики. На начало 2021 г. с месторождений, разрабатываемых Государственным концерном «Туркменгаз» и китайской СNPC International Turkmenistan, до побережья Тихого океана в общей сложности доставлено 290 миллиардов кубометров природного газа [15]. По данным Посольства Китая в Туркмении в настоящее время обе стороны обсуждают подписание специальной программы о расширении партнёрства в экономической сфере. Китай также проявляет интерес к развитию сотрудничества с Туркменией по проектам создания регионального логистического центра и инновационного города Каспия. Указанные предложения поступили от президента Туркменистана Г. Бердымухамедова в ходе первого Каспийского экономического форума (11-12 августа 2019 г.). 
Состав проектов «Пояса и пути», реализуемых в Центральной Азии

\begin{tabular}{|c|c|}
\hline Наименование проекта & Страны реализации \\
\hline \multicolumn{2}{|c|}{ В сфере транспорта } \\
\hline $\begin{array}{l}\text { Внутригосударственные железнодорожные } \\
\text { сообщения }\end{array}$ & Узбекистан \\
\hline $\begin{array}{l}\text { Межгосударственные железнодорожные } \\
\text { сообщения I и II «Европа - Китай» }\end{array}$ & Казахстан, Киргизия, Узбекистан \\
\hline Сухой порт (реконструкция) & Казахстан \\
\hline $\begin{array}{l}\text { Морской порт (строительство, } \\
\text { реконструкция) }\end{array}$ & Казахстан \\
\hline $\begin{array}{l}\text { Реконструкция автодороги Душанбе - } \\
\text { граница с Узбекистаном }\end{array}$ & Таджикистан, Узбекистан \\
\hline \multicolumn{2}{|l|}{ В сфере энергетики } \\
\hline Газопровод Центральная Азия - Китай & $\begin{array}{l}\text { Туркменистан, Узбекистан, Казахстан, } \\
\text { Китай }\end{array}$ \\
\hline Реконструкция гидроэлектростанции & Таджикистан \\
\hline Солнечная электростанция & Казахстан \\
\hline \multicolumn{2}{|l|}{ Специальные экономические зонь } \\
\hline «Хоргос-Восточные ворота» & Казахстан \\
\hline ВСЕГО & $\begin{array}{l}9 \text { из } 118(7,6 \%) \text { в т.ч. на территориях: } \\
\text { Казахстана }-6 \text {; } \\
\text { Узбекистана }-4 \text {; } \\
\text { Таджикистана - } 2 \text {; } \\
\text { Киргизии }-1 \text {; } \\
\text { Туркменистана - } 1 \text {. }\end{array}$ \\
\hline
\end{tabular}

Составлено автором. Источник: Belt and Road Initiative. Официальный сайт [25]

В поддержку глобальной инициативы «Пояс и Путь» проводятся мероприятия по формированию человеческого капитала и обмена человеческими ресурсами через совместные образовательные и культурные проекты, информирование мировой общественности о ходе реализации инициативы, издательскую деятельность. В частности, студенты из государств-участников инициативы имеют право подать заявки на получение грантов для обучения в китайских вузах [6]. Например, по численности студентов, обучающихся в вузах Китая, Казахстан находится на 9 месте после Южной Кореи, США, Японии, Тайланда, Вьетнама, России, Индии и Пакистана [2]. Правительство КНР ежегодно увеличивает число образовательных грантов для стран-участниц «Пояса и пути». После окончания вузов выпускники, имеющие инженерное (техническое) образование, получают право работать в тех китайских компаниях, которые реализуют инфраструктурно-инвестиционные проекты в Цен- 
тральной Азии. В отдельных центральноазиатских государствах (Таджикистан) государственными программами предусматривается строительство общеобразовательных школ за счёт средств правительства КНР [13]. В таких школах планируется обучение китайскому языку, основам китайской культуры и истории, в том числе в контексте инициативы «Пояс и путь». В рамках взаимодействия между Китаем и странами Ассоциации государств юго-Восточной Азии (АСЕАН) ежегодно проводится Пекинский научный лагерь для молодёжи [40]. В течение 2020 г. научный лагерь модернизирован под цели и задачи инициативы «Пояс и путь», что значительно увеличило численность его участников за счёт молодёжи из других стран, в том числе не входящих в АСЕАН. Реализуются проекты по интеграции культур стран-участниц. В рамках празднования 3-й китайской международной выставки импорта в Шанхае китайская ассоциация художников представила экспозицию, демонстрирующую более 200 работ художников из Китая и стран-участниц инициативы «Пояс и путь» $[9,18]$. Выставка «Пояс и путь», организованная Национальным художественным музеем Китая, объединила почти 200 классических китайских картин, работ маслом, скульптур и гравюр художников из страны и из-за рубежа, которые «признают важность традиционных обменов между цивилизациями Востока и Запада» [23]. При проведении 2-го Международного карнавала деликатесов в районе Чаоян г. Пекин продемонстрировано более 40 брендов из стран, участвующих в инициативе. Участниками карнавала стали около 20 тыс. человек [32]. При проведении 7-го Международного кинофестиваля «Шёлковый путь» организаторами подчеркнута важность совместного производства художественных, документальных и анимационных фильмов, а также обмен ими через кинопрокат в странах, участвующих в инициативе «Пояс и путь» [27]. В ходе международной недели культуры по парче и вышивке, состоявшейся на о. Хайнань [31], представлены работы из стран и регионов вдоль «Пояса и пути», каждый из которых демонстрировал свой собственный местный и национальный стиль. Подобные мероприятия проводятся и на территориях стран-участниц, например, в Узбекистане [3]. Издательская деятельность направлена на выпуск печатных и электронных книг и журналов, авторами которых зачастую являются лица некитайского происхождения. Например, в книге Ричарда Гриффитца (Нидерланды) «Морской шёлковый путь» анализируется необходимость такой инициативы и обосновывается «решающая роль, которую она должна сыграть в глобальном восстановлении после новой пандемии коронавируса» [24]. В целом, как свидетельствуют данные финансового планирования КНР, расходы на образование и культуру (включая туризм, спорт и СМИ) за последние три отчётных года повышаются (см. табл. 2).

Для информирования общественности о ходе и результатах реализации инициативы «Пояс и путь» в КНР создана и успешно функционирует сеть новостей «Тһе Belt and Road News Network» (BRNN) [35]. Сеть использует любые значимые информационные поводы для продвижения «Пояса и пути» в мировом информацион- 
ном пространстве. Так, BRNN опубликовала открытое письмо членам своего альянса из 205 средств массовой информации из 98 стран мира, призывая их донести до общественности послание единства и поддержки, публиковать истории о том, как страны-участницы инициативы борются вместе против пандемии коронавирусной инфекции [36]. Несмотря на распространение COVID-19, препятствующее личным международным обменам, 15 декабря 2020 г. в Пекине состоялась встреча в онлайн и оффлайн формате представителей более 70 крупных телевизионных медиа-организаций из более чем 40 стран. На повестке значилось обсуждение вопросов будущего глобального сотрудничества в рамках BRI [38].

Таблиц̧а 2

Расходы КНР в сфере образования и культуры в 2018-2020 гг. (в млн юаней)

\begin{tabular}{|l|c|c|c|}
\hline \multicolumn{1}{|c|}{ Вид расходов } & 2018 & 2019 & $2020^{*}$ \\
\hline Образование & 1731,83 & 1835,88 & 1699,09 \\
\hline $\begin{array}{l}\text { Культура, туризм, } \\
\text { спорт, СМИ }\end{array}$ & 279,38 & 308,85 & 268,93 \\
\hline
\end{tabular}

Составлено автором. Источник: Ministry of Finance the People's Republic of China [33]

Со слов официальных представителей органов власти КНР, расширение и углубление культурных, в т.ч. туристических обменов со странами, участвующими в инициативе, будет продолжено. При этом планируется на регулярной основе проводить рекламные мероприятия, использовать культурные ресурсы для развития туризма, использовать возможности и платформу, предоставляемые туризмом, для продвижения в мировое пространство культуры китайских регионов [34]. Над продвижением инициативы работают сотрудники китайских дипмиссией в странах пребывания. В интервью посла Китая в США приведены примеры успешной реализации инициативы в конкретных странах, в частности, в Казахстане. Являясь крупнейшей в мире страной, не имеющей выхода к морю, Казахстан - в результате BRI - получил доступ к Тихому океану через порт Ляньюньган в Китае. В 2014 г. в порту Ляньюньган (Китай) был создан совместный с казахскими партнёрами логистический терминал, который на сегодняшний день является основным пунктом консолидации грузопотоков в/из Казахстана [21]. К обеспечению инициативы привлекаются представители науки. В работе Международного форума «Пояс и путь» по творчеству и устойчивому развитию в постпандемическую эпоху 31 июля 2020 г. приняли участие эксперты и учёные международного состава [29]. Подобные форумы проводятся как на многосторонней, так и на двухсторонней основе с государствами-партнёрами, в частности с Таджикистаном [1].

* Снижение показателей за 2020 г. по всей видимости связано с пандемией COVID-19 (npuм. aвmopa). 
В целом, культурно-образовательные и информационные проекты, реализуемые КНР, представляют инструменты «мягкой силы», позволяющие избирательно формировать человеческий капитал в духе лояльности и поддержки реализуемых проектов. Учитывая сильное расслоение населения центральноазиатских государств по таким показателям, как уровень дохода, образования и доступа к информационным ресурсам, в т.ч. к ресурсам сети Интернет, следует предположить, что первоочередными объектами влияния являются представители социальноэкономических элит и талантливая молодёжь государств.

В противовес развитию инициативы «Пояс и путь» Президент США Д. Байден в конце марта 2021 г. предложил создать в союзе с «демократическими странами» аналог китайского инфраструктурного проекта. Об этом он заявил во время телефонного разговора с британским премьер-министром Б. Джонсоном. Ранее глава Белого дома также подчёркивал, что не позволит Китаю обогнать США по степени влияния и благосостояния [16]. В дополнение к политическому курсу правительственная структура, именуемая Global Engagement Center [30] (GEC), значительно активизировала свою работу по «китайскому вызову» внешней политике США [19]. Имеющие главную цель своей деятельности координировать усилия федерального правительства по выявлению и противодействию иностранным пропагандистским и дезинформационным действиям, направленным на подрыв или влияние на политику, безопасность или стабильность Соединенных Штатов, их союзников и странпартнёров, усилия GEC по противодействию пропаганде Коммунистической партии Китая включают в себя, в том числе, повышение осведомлённости общественности о проблемных аспектах инициативы «Пояс и путь»* .

Американским политическим руководством принимаются всевозможные меры для побуждения политических партий, общественных институтов и правительств государств по всему миру оценить риск и пересмотреть деловые сделки с китайскими государственными предприятиями, именуемые «хищническими». Так, китайскую коммуникационную строительную компанию (China Communication Construction Company - CCCC) и её дочерние компании обвиняют в такого рода сделках и представляют одним из ведущих подрядчиков, используемых Пекином в глобальной стратегии «Пояс и путь» [26]. По мнению руководства Соединённых Штатов, секретные контракты - это основной способ, которым китайские государственные предприятия работают в своём бизнесе по всему «Поясу и пути». Очевидно, существует процесс, в котором участвуют правительства, гражданское общество и журналисты, которые лучше разбираются в этой деятельности, включая условия контрактов, качество продукции, качество этих крупных инфраструктурных инвестиций, которые ищут страны, вопросы мошенничества, коррупции и взя-

\footnotetext{
*B 2020 г. GEC опубликован специальный доклад «Основы дезинформации и пропаганды,
} осуществляемые Россией» (прим. автора). 
точничества, хищнических контрактов, злоупотреблений рабочей силой, военных связей подобных китайских государственных предприятий. Имеет место также фундаментальная проблема непрозрачности, которая проявляется в китайской деятельности в целом и в китайских контрактах в частности [26]. В стратегии США для Индо-Тихоокеанского региона упоминается, что китайские государственные предприятия часто заставляют граждан работать в ужасающих условиях на проектах «Пояса и пути» [20]. Кроме того, обеспечивая реализацию проектов в рамках инициативы, Китай вводит санкции в отношении граждан и целых стран, которые своими действиями могут затруднить продвижение проектов [39].

США со своей стороны предлагают мировому сообществу использовать «надёжных» поставщиков в качестве альтернативы китайской системе, в которой китайские компании обязаны, согласно законодательству КНР, либо раскрывать, либо не раскрывать информацию, передаваемую через их системы. Сеть надёжных поставщиков является частью американского противодействия инициативе «Пояс и путь» и, в целом, китайскому государству. Оно отражает трансатлантические ценности и предоставляет необходимую альтернативу странам, которые стремятся вести бизнес на коммерчески равных условиях, не предполагающих отказ от своего суверенитета [37].

В общем, следует отметить реакцию Соединённых Штатов в ответ на активные китайские действия, которая носит декларативный, отчасти запоздалый характер. При этом основные усилия в практическом планировании деятельности в Центральной Азии сведены к насаждению института демократии, основывающейся на американской системе ценностей, предполагающей трансформацию социальноэкономической сферы, сферы безопасности и системы органов публичной власти республик под западные стандарты и бизнес-процессы. Данный вывод следует из содержания видов расходов США, предусмотренных документами бюджетного планирования на 2021 финансовый год (см. табл. 3). Каких бы то ни было практических мер по противодействию реализации проектов «Пояса и пути» пока не принимается. Американским руководством констатируются отдельные факты противоправных действий, допускаемых при реализации китайских проектов.

Таким образом, глобальная инициатива «Пояс и путь» представляет собой не только комплекс инфраструктурных и иных проектов в сфере социально-экономического развития и безопасности. С определённой осторожностью можно утверждать, что инициатива приняла форму государственной идеологии, дополняющей конкретным содержанием закреплённую китайской конституцией доктрину социализма с учётом национальной специфики. Об этом свидетельствует масштабность проводимых мероприятий, организационно-техническая и информационно-коммуникационная база которых позволяет проводить мероприятия в онлайн и оффлайн формате с привлечением экономически активных категорий населений стран-парт- 
нёров. При этом деятельность КНР и США в регионе на текущий момент не носит явный конфронтационный характер и выражается в предоставлении центральноазиатским государствам альтернатив развития по двум вариантам, предложенным Западом и Востоком. По всей видимости, отдельные проекты, реализуемые КНР в Центральной Азии, которые с геополитической точки зрения в течение всего срока реализации были выгодны Соединённым Штатам, и успешное использование Китаем в интересах BRI ситуации с пандемией 2020 г. (в частности, в сферах здравоохранения и железнодорожных перевозок) послужили стимулом для уточнения документов целеполагания и политических заявлений США в 2020-2021 гг.

Таблица 3

\section{Виды расходов США в государствах Центральной Азии}

\begin{tabular}{|c|c|}
\hline Страна & Вид расходов \\
\hline Казахстан & $\begin{array}{l}\text { Наращивание потенциала в сфере безопасности, создание усло- } \\
\text { вий по нераспространению оружия массового уничтожения. }\end{array}$ \\
\hline Киргизия & $\begin{array}{l}\text { Наращивание потенциала в сфере безопасности, создание бла- } \\
\text { гоприятных условий для американского бизнеса, реформирова- } \\
\text { ние государственного аппарата, насаждение демократических } \\
\text { институтов по западным стандартам, укрепление финансово- } \\
\text { технической основы деятельности ключевых организаций граж- } \\
\text { данского общества. }\end{array}$ \\
\hline Таджикистан & $\begin{array}{l}\text { Наращивание потенциала в сфере безопасности, создание бла- } \\
\text { гоприятных условий для американского бизнеса, реформирова- } \\
\text { ние государственного аппарата, насаждение демократических } \\
\text { институтов по западным стандартам, повышение конкуренто- } \\
\text { способности таджикских товаров, повышение качества и до- } \\
\text { ступности услуг гражданам в социально-экономической сфере. }\end{array}$ \\
\hline Узбекистан & $\begin{array}{l}\text { Наращивание потенциала в сфере безопасности, контроль за } \\
\text { осуществляемыми реформами в различных сферах государ- } \\
\text { ственного управления, повышение качества и доступности услуг } \\
\text { гражданам в социально-экономической сфере, улучшение инве- } \\
\text { стиционного климата, трансформация государственного управ- } \\
\text { ления в различных сферах по созданию привлекательных усло- } \\
\text { вий для американского бизнеса, противодействие негативной } \\
\text { пропаганде о США, создание условий по переходу системы об- } \\
\text { разования на западные стандарты. }\end{array}$ \\
\hline Туркменистан & Наращивание потенциала в сфере безопасности. \\
\hline
\end{tabular}

Составлено автором. Источник: U.S. Department of State [28] 


\section{Список литературы}

1. Лекаркин, И. Академики Китая и Таджикистана обсудили сотрудничество в рамках «Пояса и пути». - URL: https://tj.sputniknews.ru/20201122/china-Tajikistansotrudnichestvo-Poyas-put-1032319461.html (дата обращения: 04.05.2021).

2. В Поднебесной учатся более 14 тысяч казахстанских студентов. - URL: https://24.kz/ru/news/obrazovanie-i-nauka/item/288845-v-podnebesnoj-uchatsya-bolee14-000-kazakhstanskikh-studentov (дата обращения: 04.05.2021).

3. В Ташкенте открылась выставка «Узбекистан и "Пояс и путь"»// Синьхуа новости : офиц. сайт. - URL: http://russian.news.cn/2019-09/19/c_138402606.htm?utm _source=yxnews\&utm_medium $=$ desktop\&utm_referrer $=\mathrm{https} \% 3 \mathrm{~A} \% 2 \mathrm{~F} \% 2 \mathrm{Fyandex} . \mathrm{com}$ $\% 2$ Fnews\%2Fstory\%2FV_Tashkente_otkrylas_vystavka_Uzbekistan_i_Poyas_i_put-a5b665ab71639700b7cc3ca7202fd6f7 (дата обращения: 04.05.2021).

4. Генеральный консул КНР в Алматы г-н Чжан Вэй рассказывает казахстанским СМИ об итогах Второго форума высокого уровня по международному сотрудничеству «Один пояс и один путь» // Kazakhstan Today : офиц. сайт. - URL: https://www.kt.kz/rus/interview/generalnyy_konsul_knr_v_almaty_gn_chzhan_vey_rasskazyvaet_1377883891.html (дата обращения: 28.03.2021).

5. Главы Узбекистана и Китая обсудили инициативу «Один пояс, один путь». - URL: https://eadaily.com/ru/news/2021/04/29/glavy-uzbekistana-i-kitayaobsudili-iniciativu-odin-poyas-odin-put?utm_source=yxnews\&utm_medium=desktop (дата обращения: 01.05.2021).

6. Гранты на обучение в Китае One Belt - One Road, Jasmine и другие // StudyInChina.com : офиц. сайт. - URL: https://btfr.cc/ffh (дата обращения: 28.03.2021).

7. Итоги международного форума «Пояс и путь»// Центр «Стратегия развития» : офиц. сайт. - URL: https://strategy.uz/index.php?news=701\&lang=ru (дата обращения: 25.04.2021).

8. Национальная стратегия развития Кыргызской Республики на 20182040 годы. Подтвержденное финансирование инвестпроектов // Правительство Киргизской Республики : офиц. сайт. - URL: https://www.gov.kg/ru/programs/8 (дата обращения: 11.04.2021).

9. Таджикистан представил свою продукцию на международной выставке в Китаe. - URL: https:/tt.sputniknews.ru/20201106/Tajikistan-vystavka-china-1032220133.html (дата обращения: 04.05.2021).

10. Об утверждении Государственной программы инфраструктурного развития «Нұрлы жол» на 2020-2025 годы. - URL: https://www.baiterek.gov.kz/sites/ default/files/2020-02/4.pdf (дата обращения: 28.03.2021).

11. Президент Узбекистана утвердил Госпрограмму на 2021 год. Главное. URL: https://review.uz/post/prezident-uzbekistana-utverdil-gosprogrammu-na-2021-godglavnoe (дата обращения: 01.05.2021). 
12. Программа «Реальные цели, новые перспективы» // Правительство Киргизской Республики : офиц. сайт. - URL: https://www.gov.kg/ru/programs/6 (дата обращения: 28.03.2021).

13. Программа среднесрочного развития Республики Таджикистан на 20162020 гг. - URL: https://www.maorif.tj/asosi/strategiya (дата обращения: 28.03.2021).

14. Лай, И. Проверка потенциала пройдена успешно. - URL: https://iz.ru/1134 281/lai-i/proverka-potentciala-proidena-uspeshno (дата обращения: 01.05.2021).

15. Си Цзиньпин готов обсудить с Гурбангулы Бердымухамедовым продвижение сотрудничества. - URL: http://casp-geo.ru/si-tszinpin-gotov-obsudit-s-gurbanguly-berdymuhamedovym-prodvizhenie-sotrudnichestva/ (дата обращения: 01.05.2021).

16. Алексеева, Н. «У нас должна быть аналогичная инициатива»: зачем Байден предложил скопировать китайский проект «Один пояс - один путь» / Н. Алексеева, А. Медведева // Russia Today : офиц. сайт. - URL: https://russian.rt.co m/world/article/846738-odin-poyas-odin-put-dzho-baiden (дата обращения: 28.03.2021).

17. Шавкат Мирзиёев дал предложения по развитию концепции «Один пояс, один путь». - URL: https://uznews.uz/ru/article/4875/ (дата обращения: 25.04.2021).

18. Shanghai exhibition hails peace, cooperation and mutual learning // ChinaCulture.org : official site. - URL: http://en.chinaculture.org/2020-11/05/content_1486009.htm (дата обращения: 28.02.2021).

19. Advancing U.S. Engagement and Countering China in the Indo-Pacific and Beyond // U.S. Embassy and Consulate in China : official site. - URL: https://china.usembas sy-china.org.cn/advancing-u-s-engagement-and-countering-china-in-the-indo-pacificand-beyond/ (дата обращения: 22.02.2021).

20. At the 2020 Trafficking in Persons Report Launch Ceremony // U.S. Embassy and Consulate in China : official site. - URL: https://china.usembassy-china.org.cn/atthe-2020-trafficking-in-persons-report-launch-ceremony/ (дата обращения: 22.02.2021).

21. Ambassador Cui Tiankai's Op-ed on Belt and Road Initiative on Fortune Magazine // Embassy of the People's Republic of China in the United States of America : official site. - URL: http://www.china-embassy.org/eng/zmgxs/zxxx/t1657153.htm (дата обращения: 23.02.2021).

22. A new U.S. strategy for the Indo-Pacific // The National Bureau of Asian Research : official site. - URL: https://www.nbr.org/wp-content/uploads/pdfs/publica tions/sr86_cliff_June2020.pdf (дата обращения: 25.04.2021).

23. Art exhibition marks natural and cultural heritage along the Silk Road // ChinaCulture.org : official site. - URL: http://en.chinaculture.org/2020-07/31/content_1482747.htm (дата обращения: 28.02.2021).

24. Book helps to navigate the Maritime Silk Road initiative // ChinaCulture.org : official site. - URL: http://en.chinaculture.org/2020-08/21/content_1483542.htm (дата обращения: 28.02.2021). 
25. BRI Projects // Belt and Road Initiative : official site. - URL: https://www.beltroad-initiative.com/projects/ (дата обращения: 25.04.2021).

26. Briefing With Senior State Department and Commerce Officials // U.S. Embassy and Consulate in China : official site. - URL: https://china.usembassychina.org.cn/briefing-with-senior-state-department-and-commerce-officials-on-statedepartment-visa-restrictions-placed-on-individuals-from-the-peoples-republic-of-chinaand-commerce-department-restriction/ (дата обращения: 22.02.2021).

27. Collaboration drives Silk Road film festival // ChinaCulture.org : official site. URL: http://en.chinaculture.org/2020-10/19/content_1485398.htm (дата обращения: 28.02.2021).

28. Congressional Budget Justification // U.S. Department of State : official site. URL: https://www.state.gov/wp-content/uploads/2020/04/FY21-Supplementary-TablesFINAL.pdf (дата обращения: 04.05.2021).

29. Experts discuss creativity and sustainable development // ChinaCulture.org : official site. - URL: http://en.chinaculture.org/2020-08/07/content_1483048.htm (дата обращения: 28.02.2021).

30. Global Engagement Center // U.S. Department of State : official site. - URL: https://www.state.gov/bureaus-offices/under-secretary-for-public-diplomacy-and-publicaffairs/global-engagement-center/ (дата обращения: 22.02.2021).

31. Hainan to hold int'l culture week on brocade, embroidery // ChinaCulture.org : official site. - URL: http://en.chinaculture.org/2020-08/19/content_1483456.htm (дата обращения: 28.02.2021).

32. Intl Delicacy Carnival boosts cultural consumption in Beijing // ChinaCulture.org : official site. - URL: http://en.chinaculture.org/2020-10/20/content_148 5495.htm (дата обращения: 28.02.2021).

33. Ministry of Finance the People's Republic of China : official site. - URL: http://www.mof.gov.cn/en/data/ (дата обращения: 05.05.2021).

34. Shandong building culture and tourism industries at rapid pace // ChinaCulture.org : official site. $\quad-\quad$ URL: http://en.chinaculture.org/202009/22/content_1484550.htm (дата обращения: 28.02.2021).

35. The Belt and Road News Network : official site. - URL: http://en.brnn.com (дата обращения: 23.02.2021).

36. He, Yin. To defeat COVID-19 pandemic calls for joint efforts from global media // People's Daily : official site. - URL: http://en.people.cn/n3/2020/0511/c900009689118.html (дата обращения: 23.02.2021).

37. Transatlantic Dialogue on China: Managing the escalating stakes // U.S. Embassy and Consulate in China : official site. - URL: https://china.usembassychina.org.cn/transatlantic-dialogue-on-china-managing-the-escalating-stakes/ (дата обращения: 22.02.2021). 
38. TV media 'gathers' to explore international cooperation // ChinaCulture.org : official site. - URL: http://en.chinaculture.org/2020-12/16/content_1487547.htm (дата обращения: 28.02.2021).

39. United States Strategic Approach to the People's Republic of China // U.S. Embassy and Consulate in China : official site. - URL: https://china.usembassychina.org.cn/wp-content/uploads/sites/252/U.S.-Strategic-Approach-to-The-PeoplesRepublic-of-China-Report-5.24v1.pdf (дата обращения: 22.02.2021).

40. Webinar marks one-year anniversary of Beijing Science Camp for ASEAN Youth // ChinaCulture.org : official site. - URL: http://en.chinaculture.org/waccce/202008/17/content_1483667.htm (дата обращения: 28.02.2021).

\section{References}

1. Lekarkin I. Akademiki Kitaya i Tadzhikistana obsudili sotrudnichestvo v ramkakh «Poyasa i puti» [Academicians of China and Tajikistan discussed cooperation within the framework of the «Belt and Road»]. Available at: https://tj.sputniknews.ru/20201122/chin a-Tajikistan-sotrudnichestvo-Poyas-put-1032319461.html (accessed 18 August 2021).

2. More than 14 thousand Kazakhstani students study in the Celestial Empire. Available at: https://24.kz/ru/news/obrazovanie-i-nauka/item/288845-v-podnebesnoj-uchatsyabolee-14-000-kazakhstanskikh-studentov (accessed 18 August 2021). (In Russian).

3. The exhibition «Uzbekistan and the Belt and Road» was opened in Tashkent. Xinhua news: official site. Available at: http://russian.news.cn/2019-09/19/c_1384026 06.htm?utm_source=yxnews\&utm_medium $=$ desktop\&utm_referrer $=\mathrm{https} \% 3 \mathrm{~A} \% 2 \mathrm{~F} \% 2 \mathrm{Fy}$ andex.com\%2Fnews\%2Fstory\%2FV_Tash7kente_bot6 (accessed 18 August 2021). (In Russian).

4. Consul General of the People's Republic of China in Almaty, Mr. Zhang Wei, tells the Kazakh media about the results of the Second High-Level Forum on International Cooperation «One Belt and One Road». Kazakhstan Today: official site. Available at: https://www.kt.kz/rus/interview/generalnyy_konsul_knr_v_almaty_g-n_chzhan_vey_ rasskazyvaet_1377883891.html (accessed 18 August 2021). (In Russian).

5. The heads of Uzbekistan and China discussed the Belt and Road Initiative. Available at: https://eadaily.com/ru/news/2021/04/29/glavy-uzbekistana-i-kitaya-obsudiliiniciativu-odin-poyas-odin-put?utm_source=yxnews\&utm_medium=desktop (accessed 18 August 2021). (In Russian).

6. Grants for studying in China One Belt - One Road, Jasmine and others. StudyInChina.com: official site. Available at: https://btfr.cc/ffh (accessed 18 August 2021). (In Russian).

7. Results of the international forum «Belt and Road». Center for Development Strategy: official site. Available at: https://strategy.uz/index.php?news=701\&lang=ru (accessed 18 August 2021). (In Russian). 
8. National Development Strategy of the Kyrgyz Republic for 2018-2040. Confirmed financing of investment projects. Government of the Kyrgyz Republic: official site. Available at: https:/www.gov.kg/ru/programs/8 (accessed 18 August 2021). (In Russian).

9. Tajikistan presented its products at an international exhibition in China. Available at: https://t.sputniknews.ru/20201106/Tajikistan-vystavka-china-1032220133.html (accessed 18 August 2021). (In Russian).

10. On approval of the State Program for Infrastructure Development «Nurly Zhol» for 2020-2025. Available at: https://www.baiterek.gov.kz/sites/default/files/202002/4.pdf (accessed 18 August 2021). (In Russian).

11. The President of Uzbekistan approved the State Program for 2021. The main thing. Available at: https://review.uz/post/prezident-uzbekistana-utverdil-gosprogrammuna-2021-god-glavnoe (accessed 18 August 2021). (In Russian).

12. The program «Real goals, new perspectives». Government of the Kyrgyz Republic: official site. Available at: https:/www.gov.kg/ru/programs/6 (accessed 18 August 2021). (In Russian).

13. Program of medium-term development of the Republic of Tajikistan for 2016-2020. Available at: https://www.maorif.tj/asosi/strategiya (accessed 18 August 2021). (In Russian).

14. Lai I. Proverka potentsiala proidena uspeshno [Potential test passed successfully]. Available at: https://iz.ru/1134281/lai-i/proverka-potentciala-proidena-uspeshno (accessed 18 August 2021).

15. Xi Jinping is ready to discuss the promotion of cooperation with Gurbanguly Berdimuhamedov. Available at: http://casp-geo.ru/si-tszinpin-gotov-obsudit-s-gurbangu ly-berdymuhamedovym-prodvizhenie-sotrudnichestva/ (accessed 18 August 2021). (In Russian).

16. Alekseeva N., Medvedeva A. «U nas dolzhna byt' analogichnaya initsiativa»: zachem Baiden predlozhil skopirovat' kitaiskii proekt «Odin poyas — odin put'» [«We should have a similar initiative»: why Biden suggested copying the Chinese project «One Belt - One Road»]. Russia Today: official site. Available at: https://russian.rt.co m/world/article/846738-odin-poyas-odin-put-dzho-baiden (accessed 18 August 2021).

17. Shavkat Mirziyoyev made suggestions for the development of the «One Belt, One Road» concept. Available at: https:/uznews.uz/ru/article/4875/ (date of access: 25.04.2021).

18. Shanghai exhibition hails peace, cooperation and mutual learning. ChinaCulture.org: official site. Available at: http://en.chinaculture.org/2020-11/05/content_1486009.htm (accessed 18 August 2021). (In Russian).

19. Advancing U.S. Engagement and Countering China in the Indo-Pacific and Beyond. U.S. Embassy and Consulate in China: official site. Available at: https://china.usem bassy-china.org.cn/advancing-u-s-engagement-and-countering-china-in-the-indo-pacificand-beyond/ (accessed 18 August 2021). 
20. At the 2020 Trafficking in Persons Report Launch Ceremony. U.S. Embassy and Consulate in China: official site. Available at: https://china.usembassy-china.org.cn/at-the-2020trafficking-in-persons-report-launch-ceremony/ (accessed 18 August 2021).

21. Ambassador Cui Tiankai's Op-ed on Belt and Road Initiative on Fortune Magazine. Embassy of the People's Republic of China in the United States of America: official site. Available at: http://www.china-embassy.org/eng/zmgxs/zxxx/t1657153.htm (accessed 18 August 2021).

22. A new U.S. strategy for the Indo-Pacific. The National Bureau of Asian Research: official site. Available at: https://www.nbr.org/wp-content/uploads/pdfs/publica tions/sr86_cliff_June2020.pdf (accessed 18 August 2021).

23. Art exhibition marks natural and cultural heritage along the Silk Road. ChinaCulture.org: official site. Available at: http://en.chinaculture.org/2020-07/31/content_ 1482747.htm (accessed 18 August 2021).

24. Book helps to navigate the Maritime Silk Road initiative. ChinaCulture.org: official site. Available at: http://en.chinaculture.org/2020-08/21/content_1483542.htm (accessed 18 August 2021).

25. BRI Projects. Belt and Road Initiative: official site. Available at: https://www.beltroad-initiative.com/projects/ (accessed 18 August 2021).

26. Briefing With Senior State Department and Commerce Officials. U.S. Embassy and Consulate in China: official site. Available at: https://china.usembassychina.org.cn/briefing-with-senior-state-department-and-commerce-officials-on-statedepartment-visa-restrictions-placed-on-individuals-from-the-peoples-republic-of-chinaand-commerce-department-restriction/ (accessed 18 August 2021).

27. Collaboration drives Silk Road film festival. ChinaCulture.org: official site. Available at: http://en.chinaculture.org/2020-10/19/content_1485398.htm (accessed 18 August 2021).

28. Congressional Budget Justification. U.S. Department of State: official site. Available at: https://www.state.gov/wp-content/uploads/2020/04/FY21-SupplementaryTables-FINAL.pdf (accessed 18 August 2021).

29. Experts discuss creativity and sustainable development. ChinaCulture.org: official site. Available at: http://en.chinaculture.org/2020-08/07/content_1483048.htm (accessed 18 August 2021).

30. Global Engagement Center. U.S. Department of State: official site. Available at: https://www.state.gov/bureaus-offices/under-secretary-for-public-diplomacy-and-publicaffairs/global-engagement-center/ (accessed 18 August 2021).

31. Hainan to hold int'l culture week on brocade, embroidery. ChinaCulture.org: official site. Available at: http://en.chinaculture.org/2020-08/19/content_1483456.htm (accessed 18 August 2021). 
32. Intl Delicacy Carnival boosts cultural consumption in Beijing. ChinaCulture.org: official site. Available at: http://en.chinaculture.org/2020-10/20/content_148 5495.htm (accessed 18 August 2021).

33. Ministry of Finance the People's Republic of China: official site. Available at: http://www.mof.gov.cn/en/data/ (accessed 18 August 2021).

34. Shandong building culture and tourism industries at rapid pace. ChinaCulture.org: official site. Available at: http://en.chinaculture.org/2020-09/22/content_14845 50.htm (accessed 18 August 2021).

35. The Belt and Road News Network: official site. Available at: http://en.brnn.com (accessed 18 August 2021).

36. He Yin. To defeat COVID-19 pandemic calls for joint efforts from global media. People's Daily: official site. Available at: http://en.people.cn/n3/2020/0511/c900009689118.html (accessed 18 August 2021).

37. Transatlantic Dialogue on China: Managing the escalating stakes. U.S. Embassy and Consulate in China: official site. Available at: https://china.usembassychina.org.cn/transatlantic-dialogue-on-china-managing-the-escalating-stakes/ (accessed 18 August 2021).

38. TV media 'gathers' to explore international cooperation. ChinaCulture.org: official site. Available at: http://en.chinaculture.org/2020-12/16/content_1487547.htm (accessed 18 August 2021).

39. United States Strategic Approach to the People's Republic of China. U.S. Embassy and Consulate in China: official site. Available at: https://china.usembassychina.org.cn/wp-content/uploads/sites/252/U.S.-Strategic-Approach-to-The-PeoplesRepublic-of-China-Report-5.24v1.pdf (accessed 18 August 2021).

40. Webinar marks one-year anniversary of Beijing Science Camp for ASEAN Youth. ChinaCulture.org: official site. Available at: http://en.chinaculture.org /waccee/2020-08/17/content_1483667.htm (accessed 18 August 2021). 